\title{
A Simple Way to Produce $\gamma$-Alumina From Aluminum Cans by Precipitation Reactions
}

\author{
Ysla França Adans ${ }^{a}$, André Rosa Martins ${ }^{a}$, Rodrigo Estevam Coelho ${ }^{b}$, Cesário Francisco das Virgens ${ }^{c}$,
} Adriana Daniela Ballarini ${ }^{d}$ Luciene Santos Carvalho ${ }^{a}$

${ }^{a}$ Grupo de Pesquisa em Materiais e Catálise, Instituto Federal da Bahia, Campus Camaçari, Loteamento Espaço Alpha, s/n, BA 522, Limoeiro, 42.802-590, Camaçari, BA, Brazil

${ }^{b}$ Grupo de Pesquisa em Processamento e Caracterização de Materiais, Instituto Federal da Bahia, Rua Emídio dos Santos, s/n, Barbalho, 40.301-015, Salvador, BA, Brazil

${ }^{c}$ Grupo de Estudos em Materiais e Catálise, Universidade do Estado da Bahia - UNEB, Rua Silveira Martins, 2555, Cabula, 41.150-000, Salvador, BA, Brazil

'Instituto de Investigaciones en Catálisis y Petroquímica “Ing. José Miguel Parera" - INCAPE, Facultad de Ingeniería Química - FIQ, Universidad Nacional del Litoral - UNL, Colectora Ruta Nacional $N^{\circ}$ 168, Km 0, Paraje El Pozo, 3000, Santa Fe, Argentina

Received: April 18, 2016; Revised: June 18, 2016; Accepted: June 25, 2016

In this paper, a new way for $\gamma$-alumina synthesis was proposed, the raw material being aluminum powders obtained by high-energy milling of aluminum cans. This seems a good option for this metal recycling and energy saving, as well as hydrogen production. The materials were prepared by precipitation techniques, in which aluminum powders reacted with hydrochloric acid, giving aluminum chloride, which was subsequently transformed into aluminum hydroxide by reaction with ammonium hydroxide or sodium hydroxide as precipitant agents, and finally into $\gamma$-alumina by calcination. Results showed that the used preparation methods gave a $\gamma$-alumina structure, confirmed by XRD, with surface areas values (174 and $204 \mathrm{~m}^{2} \mathrm{~g}^{-1}$ ) close to those of a commercial $\gamma$-alumina Cyanamid Ketjen $\left(180 \mathrm{~m}^{2} \mathrm{~g}^{-1}\right)$ or an alumina prepared by a typical precipitation route $\left(203 \mathrm{~m}^{2} \mathrm{~g}^{-1}\right)$. Using sodium hydroxide as precipitant agent turned out to be more ecologically compatible since it did not release harmful environmental compounds.

Keywords: Precipitation, $\gamma$-Alumina, Aluminum Cans, High-energy Milling, Recycling

\section{Introduction}

$\gamma$-Alumina is widely employed as a catalyst or catalyst support in several chemical processes, such as ammonia synthesis, synthesis gas and hydrogen production, oils hydrogenation, petroleum refining, automotive emissions control, among others ${ }^{1,2}$. Some characteristics that make it attractive for these applications are its high surface area, high thermal and chemical stability and high mechanical strength $^{2,3}$. However, alumina is mainly produced by Bayer process ${ }^{4}$, a high-energy consumption technology. On the other hand, alumina can be obtained by precipitation methods ${ }^{5}$, by sol-gel methods ${ }^{6}$, or even from kaolin ${ }^{7,8}$.

It is known that the aluminum cans recycling saves up to $95 \%$ energy. By recycling $1 \mathrm{~kg}$ aluminum cans, for instance, one can save $8 \mathrm{~kg}$ bauxite, $4 \mathrm{~kg}$ chemical products and 14 $\mathrm{kWh}$ power can be saved ${ }^{9}$. Recycling of aluminum is then of great interest from economic, energetic and environmental perspectives. In this line, with goal to contribute with new routes of this metal recycling, researchers ${ }^{10-13}$ proposed the conversion of aluminum scrap from beverage cans. These methods involve expensive reactants or complexes reactions or releasing of harmful compounds to the environment, as $\mathrm{SO}_{3}$. The majority employs sol-gel process in the synthesis of alumina and all of them use aluminum scraps and sulfuric acid or mercury compounds in the reactions.

The aim of this study was to develop a different route for $\gamma$-alumina synthesis, from using aluminum powders obtained by high-energy milling of aluminum cans as starting material. Using powders instead of aluminum scraps is interesting because increases the contact surface and hence the rate of chemical reactions and it is not necessary sulfuric acid to digest the sample. According to the proposed method, two subsequent precipitation reactions were carried out: first aluminum with hydrochloric acid and then the aluminum chloride formed with sodium hydroxide or ammonium hydroxide as precipitating agents of aluminum hydroxide gel. Other acids such as nitric or sulfuric ones could also have been used to obtain an intermediate aluminum salt such as aluminum nitrate or aluminum sulfate, respectively. However, sulfur oxides $\left(\mathrm{SO}_{\mathrm{x}}\right)$ or nitrogen oxides $\left(\mathrm{NO}_{\mathrm{x}}\right)$ could be formed as byproducts, which would cause environmental damage if released for atmosphere.

Structure and morphology of the materials were investigated by XRD, SEM, BET surface area and pore properties, and were compared with those of an alumina prepared by aluminum hydroxide precipitation from aluminum nitrate and ammonium hydroxide. 


\section{Materials and Methods}

\subsection{Obtaining aluminum powders}

The aluminum powders used for $\gamma$-alumina production were obtained through aluminum cans high-energy milling using a ball mill. The ink was removed from the cans using varnish solvent and then the cans were cut into $5 \mathrm{~mm}$ squares. The material was processed in a horizontal attritor mill, designed and assembled by Coelho $^{14}$. Milling was performed at $1000 \mathrm{rpm}$ for $1 \mathrm{~h}$.

\subsection{Preparation of $\gamma$-alumina from aluminum powders}

\subsubsection{Al reaction with $\mathrm{HCl}$ and subsequently with $\mathrm{NaOH}$}

According to this method, $4 \mathrm{~g}$ aluminum powder were weighted in a beaker and after addition of water $(100 \mathrm{~mL})$

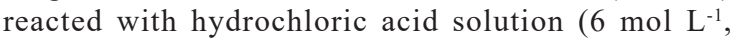
$100 \mathrm{~mL}$ ), drop-to-drop, under constant stirring, producing aluminum chloride $\left(\mathrm{AlCl}_{3}\right)$, as described by Eq. 1 .

$$
2 \mathrm{Al}+6 \mathrm{HCl} \rightarrow 2 \mathrm{AlCl}_{3}+3 \mathrm{H}_{2}
$$

Reactant addition was slow $\left(3.0 \mathrm{~mL} \mathrm{~min}^{-1}\right)$, because the reaction occurs violently and releases large amounts of heat and hydrogen. Considering the stoichiometry of this reaction from $100 \mathrm{~g}$ of aluminum are produced $125 \mathrm{~L}$ of hydrogen, that if collected and stored, it can be used as fuel. This is the goal of several studies ${ }^{15,16}$. However, the aim of this work it was not hydrogen storage. Then, due to the high inflammability of the produced hydrogen, it was released to the atmosphere taking adequate safety measures during the experiments.

Aluminum chloride was then converted into aluminum hydroxide by reaction with sodium hydroxide solution (6 mol L-1), added drop-to-drop $\left(8.0 \mathrm{~mL} \mathrm{~min}^{-1}\right)$ and under stirring, at room temperature. Eq. 2 represents this reaction.

$$
\mathrm{AlCl}_{3}+3 \mathrm{NaOH} \rightarrow \mathrm{Al}(\mathrm{OH})_{3}+3 \mathrm{NaCl}
$$

After maturation under constant stirring by $24 \mathrm{~h}$, the mixture was separated by centrifugation and the solid was washed with ammonium hydroxide solution $(1 \%)$. The gel obtained which was not white as aluminum hydroxide, but pink, was dried $\left(110{ }^{\circ} \mathrm{C}, 24 \mathrm{~h}\right)$, triturated in agate, sieved (100-200 mesh) and calcined at $800{ }^{\circ} \mathrm{C}$ for $4 \mathrm{~h}$. According to the thermal transformation sequence of the aluminum hydroxides ${ }^{17}$, the $\gamma$-alumina formation with high surface area, takes place by heating the boehmite precursor $(\mathrm{AlOOH})$ between $450-750{ }^{\circ} \mathrm{C}$. However, in this work, the chosen calcination temperature was $800{ }^{\circ} \mathrm{C}$, considering that most of catalytic processes, which employ alumina as catalyst or support, operate at high temperatures in the range of $600-900{ }^{\circ} \mathrm{C}$. This is the case, for example, of methane steam reforming reactions to produce hydrogen and syngas ${ }^{18}$. The goal was to assure the formation and preservation of $\gamma$-alumina phase in the reaction temperatures.
The prepared sample was named LS1000-1. By this method were obtained $10 \mathrm{~g}$ of dried sample and $6 \mathrm{~g}$ of calcined sample (alumina). The calcined sample was like brown.

\subsubsection{Al reaction with $\mathrm{HCl}$ and subsequently with $\mathrm{NH}_{4} \mathrm{OH}$}

Another synthesis was performed replacing sodium hydroxide by ammonium hydroxide as the precipitating agent. The preparation procedure was the same described above and the reaction between aluminum chloride and ammonium hydroxide occurred as shown in Eq. 3. The use of ammonium hydroxide as the precipitating agent is interesting because during the calcination step $\left(800^{\circ} \mathrm{C}, 4 \mathrm{~h}\right)$ ammonia $\left(\mathrm{NH}_{3}\right)$ and hydrochloric gas $(\mathrm{HCl})$ are eliminated by ammonium chloride decomposition (Eq. 4), and thus do not contaminate the final solid. However, the released gases are harmful to health and the environment. The obtained sample was named LA1000-1. The yield after drying and calcination was similar to that obtained with LS1000-1 sample, and the color was like brown too.

$$
\begin{gathered}
\mathrm{AlCl}_{3}+3 \mathrm{NH}_{4} \mathrm{OH} \rightarrow \mathrm{Al}(\mathrm{OH})_{3}+3 \mathrm{NH}_{4} \mathrm{Cl} \\
\mathrm{NH}_{4} \mathrm{Cl} \rightarrow \mathrm{NH}_{3}+\mathrm{HCl}
\end{gathered}
$$

\subsection{Preparation of $\gamma$-alumina by conventional method}

In order to compare the textural properties of the $\gamma$-alumina produced from aluminum powders with those of an alumina prepared by a conventional method, the material was also obtained by simultaneous addition of $250 \mathrm{~mL}$ aluminum nitrate solution $\left(1.0 \mathrm{~mol} \mathrm{~L}^{-1}\right)$ and $200 \mathrm{~mL}$ concentrated ammonium hydroxide (30-32\%) into a beaker containing water $(100 \mathrm{~mL})$ under constant stirring and $\mathrm{pH} 9-10$. After reactant addition, the system was kept under stirring for $24 \mathrm{~h}$. Then, the white material was centrifuged and washed with ammonium hydroxide, and the gel obtained was dried $\left(110^{\circ} \mathrm{C}, 24 \mathrm{~h}\right)$, triturated in agate, sieved (100-200 mesh) and calcined at $800{ }^{\circ} \mathrm{C}$ for $4 \mathrm{~h}$. The yield was similar to that of the samples prepared by the proposed methods. This sample was identified as CA. Calcined solid was white.

\subsection{Characterization of the solids obtained by different methods}

The thermal behavior of non-calcined materials was evaluated by thermogravimetric analysis (TGA), heating the sample from 22 to $950{ }^{\circ} \mathrm{C}$, under $\mathrm{N}_{2}$ atmosphere. A TGA 51-H Shimadzu equipment was used.

Scanning Electron Microscopy (SEM) images of calcined samples were obtained through VEGA 3 Tesca equipment at $15 \mathrm{kV}$. Energy Dispersive X-Ray Spectroscopy (EDS) analysis to identify the chemical qualitative composition was performed in an $\mathrm{X}$-act Oxford Instruments apparatus coupled to the electron microscope.

Samples crystalline phases were identified by X-ray diffraction (XRD). During the experiments performed in 
Shimadzu XRD 7000, samples were exposed to $\mathrm{CuKa}$ radiation, generated at $30 \mathrm{kV}$ and $20 \mathrm{~mA}$. The scan was from 10 to $80^{\circ}$.

Specific surface area and porosity analyzes were made by nitrogen adsorption measurements, at $-196^{\circ} \mathrm{C}(77 \mathrm{~K})$, in an ASAP 2420 equipment, using a 200-300 mg of sample.

\section{Results and Discussion}

\subsection{TGA/DTG}

Figure 1 shows TGA and DTG (derivate) profiles of LS1000-1 and LA1000-1 samples, non-calcined (NC), prepared from aluminum powders. The curves showed three regions of mass loss. The first one, between 22 e $117^{\circ} \mathrm{C}$, with mass loss values around $14 \%$, is related to evaporation of physically adsorbed water on the solid ${ }^{19,20}$. For LS1000-1, the mass loss that can be better observed by DTG peaks in the range of $180-340^{\circ} \mathrm{C}$ comes from the release of chemisorbed water, which takes place around $250{ }^{\circ} \mathrm{C}^{8}$. In this case, thermal decomposition of $\mathrm{NaCl}$ (a by-product of aluminum chloride reaction with sodium hydroxide (Eq. 2)) does not happen, so the mass loss is small. On the other hand, the well defined endothermic peak for LA1000-1 DTG is due to ammonium chloride decomposition that is a byproduct of aluminum chloride reaction with ammonium hydroxide (Eq. 3). During the decomposition, ammonia and hydrochloric gas are released (Eq. 4), this producing a greater mass loss. The third region corresponds to an endothermic peak between 330 and $570{ }^{\circ} \mathrm{C}$, and it can be related to the loss of the aluminum hydroxide hydration water, producing alumina by dihydroxylation ${ }^{19}$, according to Eq. 5 . The mass loss values observed in the TGA experiments (30-40\%) are in agreement with the difference between the mass values determined before and after calcination of the samples.

$$
2 \mathrm{Al}(\mathrm{OH})_{3} \rightarrow \mathrm{Al}_{2} \mathrm{O}_{3}+3 \mathrm{H}_{2} \mathrm{O}
$$

\section{2. $S E M / E D S$}

Solids EDS spectra prepared from aluminum powders (Figure 2) indicate the presence of metals such as iron, manganese, magnesium and potassium in the solids,

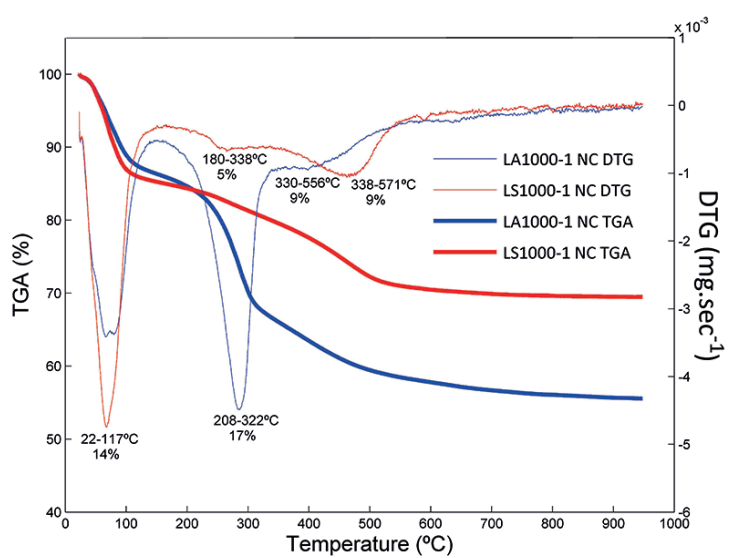

Figure 1: TGA and DTG profiles: LS1000-1 and LA1000-1, noncalcined (NC).

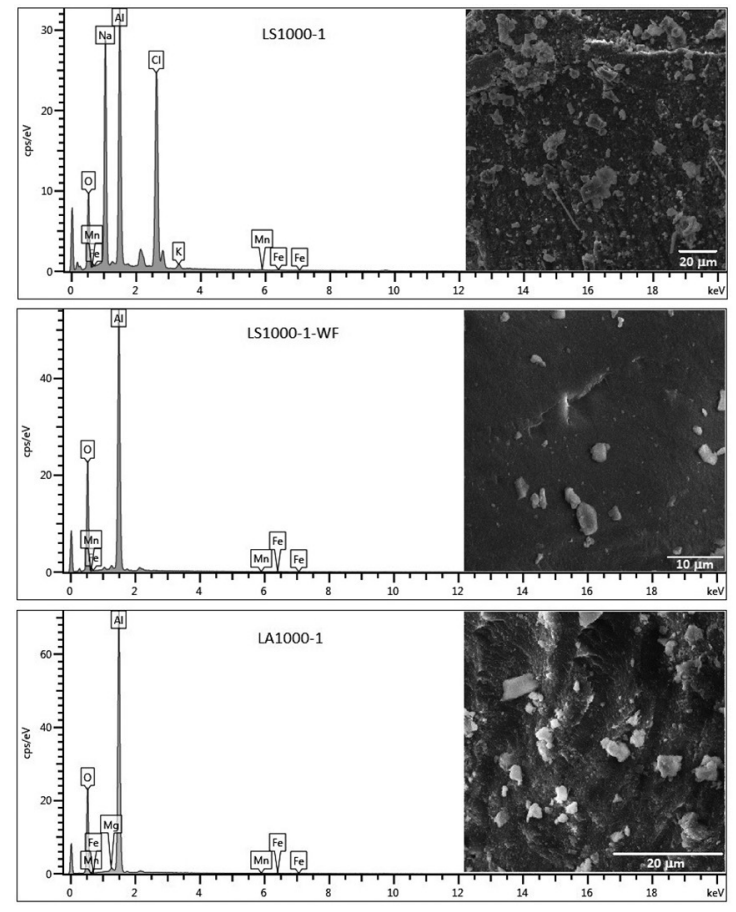

Figure 2: EDS spectra and SEM images of the calcined samples at $800{ }^{\circ} \mathrm{C}$, obtained from aluminum powders.

confirming that pink color of the gel obtained is really due to the presence of these contaminants, coming from the cans. In fact, Liu et al. ${ }^{10}$ determined the quantitative chemical composition of beverage cans and founded the presence of $97.1 \mathrm{wt} \% \mathrm{Al}, 1.08 \mathrm{wt} \% \mathrm{Mg}, 0.86 \mathrm{wt} \% \mathrm{Mn}, 0.59 \mathrm{wt} \% \mathrm{Fe}$ and $0.33 \mathrm{wt} \%$ other metals. In this work, the detected amount of contaminants was less $1.0 \mathrm{wt} \%$. At low levels, these metals can bring beneficial effects on alumina-based catalysts, such as improvements in the structural and textural properties and catalytic performance. $\mathrm{Mg}$ presence, for example, that has basic character, diminishes the alumina acidity, changing the catalyst activity and selectivity in acid catalyzed reactions. In this way prevents the formation and coke deposition, increasing the catalysts stability during methane steam reforming ${ }^{21}$ or ethanol steam reforming ${ }^{22}$. Nurunnabi and coworkers ${ }^{23}$ showed that $\mathrm{Mn}$ addition to $\mathrm{Ru} / \gamma-\mathrm{Al}_{2} \mathrm{O}_{3}$ catalysts increases their resistance to deactivation during FischerTropsch reaction. It was also observed a synergistic effect between $\mathrm{Fe}$ and $\mathrm{Co}$ when a small amount of $\mathrm{Fe}$ is added to $\mathrm{Co} / \mathrm{Al}_{2} \mathrm{O}_{3}$ catalyst, which improves the catalyst performance in the ethanol steam reforming ${ }^{24}$.

Analyzing the EDS spectrum of LS1000-1 sample, it was noted that not only the above metals but sodium and chlorine as well were also present. These elements were not removed during the calcination step, remaining as sodium chloride $(\mathrm{NaCl})$ in the solid. In order to remove the salt, the material was washed with water, vacuum filtered, dried at $110{ }^{\circ} \mathrm{C}$ and calcined at $800{ }^{\circ} \mathrm{C}$, and the LS1000-1-WF sample was obtained. EDS spectrum was recorded again (Figure 2), showing that the washing process was efficient to eliminate the $\mathrm{NaCl}$. Regarding LA1000-1, chloride was not found, since it was eliminated during ammonium chloride decomposition in the calcination step, according to TGA/ 
DTG results. It was also possible to observe, from SEM images, that the solids morphologies were similar, with heterogeneous particle sizes. However, LS1000-1 sample showed a smooth surface, while fissures can be noted on the surface of LA1000-1 one, probably resulting from empty spaces generated by gases released during calcination.

\section{3. $X R D$}

Calcined at $800{ }^{\circ} \mathrm{C}$ and non-calcined solids XRD profiles are shown in Figure 3. It can be seen that the main phase found in the non-calcined samples was the boehmite (JCPDS 21-1307 card), which is transformed into $\gamma$-alumina (JCPDS 29-0063 card) after calcination. Similar profiles of $\gamma$-alumina were obtained by other authors ${ }^{25,26}$. Regarding LS1000-1 NC and LA1000-1 NC samples, besides boehmite phase $\mathrm{NaCl}$ (JCPDS 05-0628 card) and $\mathrm{NH}_{4} \mathrm{Cl}$ (JCPDS PDF 730365 card) were identified, respectively. After the calcination step, $\mathrm{NH}_{4} \mathrm{Cl}$ was removed from LA1000-1, but NaCl remained in LS10001, in agreement with EDS results. However, the washing procedure with water and subsequent calcination contributed to the salt removal so that only $\gamma$-alumina phase in the sample LS1000-1-WF was detected. LS1000-1 sample was washed with water to dissolve and eliminated $\mathrm{NaCl}$, and then dried and calcined to produce LS1000-1-WF sample. After these steps, and based on the thermal behaviors observed by TGA (Figure 1) and by XRD profiles (Figure 3), it can be noted that this technique of alumina preparation had the advantage of avoid the emission of harmful chemical compounds to the atmosphere, differently from what happens with LA1000-1.

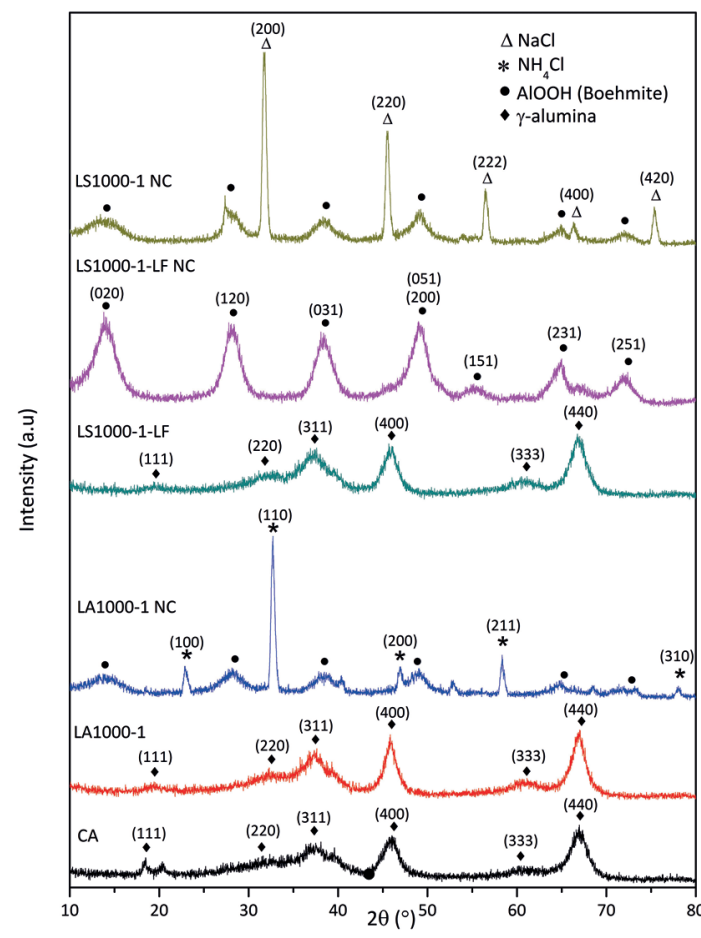

Figure 3: XRD profiles of the non-calcined (NC) and calcined solids at $800^{\circ} \mathrm{C}$.

\subsection{Surface Area and Porosity}

Specific surface area $(\mathrm{Sg})$ and pore volume $(\mathrm{Vp})$ values of calcined solids at $800{ }^{\circ} \mathrm{C}$ are shown in Table 1 . Specific surface areas were calculated by Brunauer-Emmett-Teller (BET) method ${ }^{27}$, while pore volumes were determined by Barret-Joyner-Halenda (BJH) method $^{28}$. It was observed that all materials had high surface area values (174 to $204 \mathrm{~m}^{2} \mathrm{~g}^{-1}$ ) and low pore volumes $\left(0.3 \mathrm{~cm}^{3} \mathrm{~g}^{-1}\right)$, being suitable to be used as catalyst support. Comparing the alumina samples prepared from aluminum powders with those obtained by the conventional method, it was noted that when sodium hydroxide is used as precipitant (LS1000-1 WF) the surface area value is similar to CA sample and higher than the one prepared using ammonium chloride as precipitating agent (LA1000-1). In this case, the lowest surface area can be correlated with the material morphology, as observed by SEM (Figure 3), and it comes from the empty spaces produced by the released gases. Furthermore, the textural properties of all alumina samples were similar to those of a Cyanamid Ketjen CK $300\left(180 \mathrm{~m}^{2} \mathrm{~g}^{-1}\right.$ surface area and $0.5 \mathrm{~cm}^{3} \mathrm{~g}^{-1}$ pore volume).

Table 1: Specific surface area values $(\mathrm{Sg})$ and pore volume values $(\mathrm{Vp})$ of the calcined samples at $800^{\circ} \mathrm{C}$.

\begin{tabular}{lcc}
\hline Sample & $\mathrm{Sg}\left(\mathrm{m}^{2} \mathrm{~g}^{-1}\right)$ & $\mathrm{Vp}\left(\mathrm{cm}^{3} \mathrm{~g}^{-1}\right)$ \\
\hline CA & 203 & 0.32 \\
LS1000-1-WF & 204 & 0.35 \\
LA1000-1 & 174 & 0.33 \\
\hline
\end{tabular}

Nitrogen adsorption-desorption isotherms and pore size distribution of the samples obtained from aluminum powder and aluminum nitrate are shown in Figure 4. It can be observed that all of the samples exhibited similar profiles, corresponding to a typical Type IV hysteresis, whose loops at a $\mathrm{P} / \mathrm{Po}$ range of $0.5-1.0$ are associated with the filling and emptying of the mesopores by capillary condensation ${ }^{29}$. This confirmed that in this work were prepared mesoporous materials. However, differences in the hysteresis loop shapes can be noted, indicating probable changes in pores nature. LA1000-1 sample showed a Type H4 hysteresis loop, which not terminate in plateau at high $\mathrm{P} / \mathrm{Po}$ and are given by slitshaped pores. This is in agreement with morphology observed by SEM. In contrast, the others samples (LS1000-1-WF and CA) showed Type H2 hysteresis loops, whose pore structures tend to be made up of interconnected networks of pores of different size and shape ${ }^{21}$. The pore size distribution was unimodal in all cases with pores in the range of 20-100 $\AA$. For alumina prepared by typical method, with aluminum nitrate (CA), occurred a little shift of the hysteresis loop to higher values of relative pressures, indicating that the mesopores volume increased, with domain around of $65 \AA$.

\section{Conclusions}

This work has shown the feasibility of $\gamma$-alumina production from aluminum powder, obtained through high- 

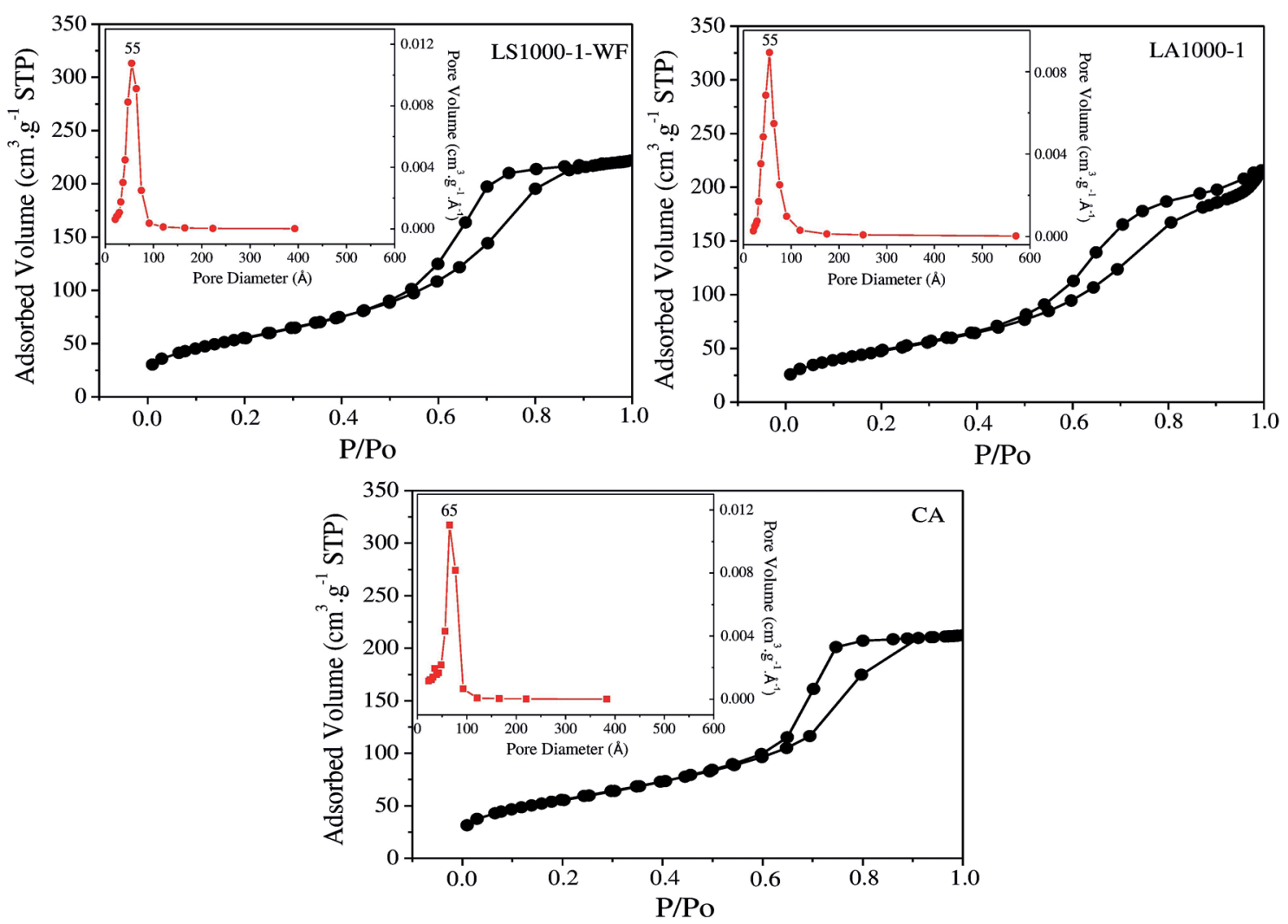

Figure 4: Nitrogen adsorption-desorption isotherms and pore size distribution curves (inserted into the graphics) for the calcined samples at $800^{\circ} \mathrm{C}$.

energy milling of aluminum cans, by precipitation methods. This is a promising route not only from the economic and energetic but also ecological and social perspective and it represents a promising way of aluminum recycling. By means of reacting aluminum powder with hydrochloric acid and subsequently with ammonium hydroxide or sodium hydroxide, $\gamma$-alumina with high surface area would be suitable for several uses, such as catalyst support. The reaction of aluminum with hydrochloric acid is very relevant because it is one of the routes by which hydrogen, an eco-friendly fuel, can be produced. By comparing the precipitating agents used, it could be observed that sodium hydroxide has more advantages than ammonium hydroxide, since there is no need to eliminate harmful environmental products, and the $\gamma$-alumina showed high surface area $\left(204 \mathrm{~m}^{2} \mathrm{~g}^{-1}\right)$, close to those of a commercial alumina $\left(180 \mathrm{~m}^{2} \mathrm{~g}^{-1}\right)$ or the one prepared by a typical precipitation method $\left(203 \mathrm{~m}^{2} \mathrm{~g}^{-1}\right)$. Therefore, the proposed route is simple and provides a way to get both alumina and hydrogen in a sustainable manner, from aluminum cans, generally discarded after use. The yield of the $\gamma$-alumina prepared from the aluminum powders was similar the one obtained by conventional precipitation method, with the additional advantage of energy saving by recycling. The formed phase was stable at $800{ }^{\circ} \mathrm{C}$. The presence of contaminating metals in low concentrations may even be beneficial if the alumina is used as catalyst support.

\section{Acknowledgments}

The authors would like to thank to IFBA Instituto Federal da Bahia (Brazil) and CONICET Consejo Nacional de Investigaciones Científicas y Técnicas (Argentina) for the financial support, to CETENE Centro de Tecnologias Estratégicas do Nordeste (Brazil) for the surface area and porosity measurements and also to Carina Soares do Nascimento (IFBA) for the SEM images.

\section{References}

1. Dörre E, Hübner H. Alumina: Processing, Properties, and Applications. New York: Springer; 1984.

2. Lee J, Jeon H, Oh DG, Szanyi J, Kwak JH. Morphologydependent phase transformation of $\gamma-\mathrm{Al}_{2} \mathrm{O}_{3}$. Applied Catalysis A: General. 2015;500:58-68.

3. Itoh T, Uchida T, Matsubara I, Izu N, Shin W, Miyazaki H, et al. Preparation of $\gamma$-alumina large grain particles with large specific surface area via polyol synthesis. Ceramics International. 2015;41(3 Part A):3631-3638.

4. Martin ES, Weaver ML. Synthesis and properties of high purity alumina. American Ceramic Society Bulletin. 1993;72(7):71-77.

5. Wang S, Li X, Wang S, Li Y, Zhai Y. Synthesis of $\gamma$-alumina via precipitation in ethanol. Materials Letters. 2008;62(20):3552-3554. 
6. Adraider Y, Hodgson SNB, Sharp MC, Zhang ZY, Nabhani F, Al-Waidh A, et al. Structure characterisation and mechanical properties of crystalline alumina coatings on stainless steel fabricated via sol-gel technology and fibre laser. Journal of the European Ceramic Society. 2012;32(16):4229-4240.

7. Hosseini SA, Niaei A, Salari D. Production of $\gamma-\mathrm{Al}_{2} \mathrm{O}_{3}$ from Kaolin. Open Journal of Physical Chemistry. 2011;1(2):23-27.

8. Salahudeen N, Ahmed AS, Al-Muhtaseb AH, Dauda M, Waziri SM, Jibril BY. Synthesis of gamma alumina from Kankara kaolin using a novel technique. Applied Clay Science. 2015;105106:170-177.

9. Verran GO, Kurzawa U. An experimental study of aluminum can recycling using fusion in induction furnace. Resources, Conservation and Recycling. 2008;52(5):731-736.

10. Liu W, Niu T, Yang J, Wang Y, Hu S, Dong Y, et al. Preparation of micron-sized alumina powders from aluminium beverage can by means of sol-gel process. Micro and Nano Letters. 2011;6(10):852-854.

11. Asencios YJ, Sun-Kou MR. Synthesis of high-surface-area $\gamma-\mathrm{Al}_{2} \mathrm{O}_{3}$ from aluminum scrap and its use for the adsorption of metals: $\mathrm{Pb}(\mathrm{II}), \mathrm{Cd}(\mathrm{II})$ and $\mathrm{Zn}(\mathrm{II})$. Applied Surface Science. 2012;258(24):10002-10011.

12. Chotisuwan S, Sirirak A, Har-Wae P, Wittayakun J. Mesoporous alumina prepared from waste aluminum cans and used as catalytic support for toluene oxidation. Materials Letters. 2012;70:125-127.

13. Matori KA, Wah LC, Hashim M, Ismail I, Zaid MHM. Phase Transformations of $\alpha$-Alumina Made from Waste Aluminum via a Precipitation Technique. International Journal of Molecular Sciences. 2012;13(12):16812-16821.

14. Coelho RE, inventor; Instituto Federal de Educação, Ciência e Tecnologia da Bahia, assignee. Moinho de alta energia com eixo aletado do tipo horizontal. Brazilian Patent PI 1106612-1 A2. 2015 Aug 11.

15. Durbin DJ, Malardier-Jugroot C. Review of hydrogen storage techniques for on board vehicle applications. International Journal of Hydrogen Energy. 2013;38(34):14595-14617.

16. Dutta S. A review on production, storage of hydrogen and its utilization as an energy resource. Journal of Industrial and Engineering Chemistry. 2014;20(4):1148-1156.

17. Souza Santos P, Souza Santos H, Toledo SP. Standard transition aluminas. Electron microscopy studies. Materials Research. 2000;3(4):104-114.
18. Roh HS, Jun KW, Dong WS, Chang JS, Park SE, Joe YI. Highly active and stable $\mathrm{Ni} / \mathrm{Ce}-\mathrm{ZrO}_{2}$ catalyst for $\mathrm{H}_{2}$ production from methane. Journal of Molecular Catalysis A: Chemical. 2002;181(1-2):137-142.

19. Alvaro-Munoz T, Marquez-Alvarez C, Sastre E. Aluminium chloride: A new aluminium source to prepare SAPO-34 catalysts with enhanced stability in the MTO process. Applied Catalysis A: General. 2014;472:72-79.

20. Chen YM, Wang MK, Huang PM, Tsao TM, Lin KC. Influence of catechin on precipitation of aluminum hydroxide. Geoderma. 2009;152(3-4):296-300.

21. Carvalho LS, Martins AR, Reyes P, Oportus M, Albonoz A, Vicentini V, et al. Preparation and characterization of $\mathrm{Ru} /$ $\mathrm{MgO}-\mathrm{Al}_{2} \mathrm{O}_{3}$ catalysts for methane steam reforming. Catalysis Today. 2009;142(1-2):52-60.

22. Contreras JL, Salmones J, Colín-Luna JA, Nuño L, Quintana B, Córdova I, et al. Catalysts for $\mathrm{H}_{2}$ production using the ethanol steam reforming (a review). International Journal of Hydrogen Energy. 2014;39(33):18835-18853.

23. Nurunnabi M, Murata K. Okabe K, Inaba M, Takahara I. Performance and characterization of $\mathrm{Ru} / \mathrm{Al}_{2} \mathrm{O}_{3}$ and $\mathrm{Ru} / \mathrm{SiO}_{2}$ catalysts modified with $\mathrm{Mn}$ for Fischer-Tropsch synthesis. Applied Catalysis A: General. 2008;340(2):203-211.

24. Kazama A, Sekine Y, Oyama K, Matsukata M, Kikuchi E. Promoting effect of small amount of Fe addition onto Co catalyst supported on $\alpha-\mathrm{Al}_{2} \mathrm{O}_{3}$ for steam reforming of ethanol. Applied Catalysis A: General. 2010;383(1-2):96-101.

25. Lv Y, Li D, Tang P, Feng Y. A simple and promoter free way to synthesize spherical $\gamma$-alumina with high hydrothermal stability. Materials Letters. 2015;155:75-77.

26. Bazyari A, Mortazavi Y, Khodadadi AA, Thompson LT, Tafreshi $\mathrm{R}$, Zaker A, et al. Effects of alumina phases as nickel supports on deep reactive adsorption of (4,6-dimethyl) dibenzothiophene: Comparison between $\gamma, \delta$, and $\theta$-alumina. Applied Catalysis B: Environmental. 2016;180:312-323.

27. Brunauer S, Emmet PH, Teller E. Adsorption of Gases in Multimolecular Layers. Journal of the American Chemical Society. 1938;60(2):309-319.

28. Barrett EP, Joyner LG, Halenda PP. The Determination of Pore Volume and Area Distributions in Porous Substances. I. Computations from Nitrogen Isotherms. Journal of the American Chemical Society. 1951;73(1):373-380.

29. Rouquerol J, Rouquerol F, Llewellyn P, Maurin G. Sing KSW. Adsorption by Powders and Porous Solids: Principles, Methodology and Applications. London: Academic Press; 2013. 